\title{
Study of the Optimum Thermal Insulation Thickness of a Calorimeter Wound with Linen Insulation
}

\author{
Mame Fadiamé THIAM ${ }^{1}$, Seydou FAYE ${ }^{2}$, Babou DIONE ${ }^{2 \#}$ \\ ${ }^{1}$ Higher Institute of Vocational Education of Matam, Senegal. \\ Technology, University Cheikh Anta Diop, Dakar, Senegal. \\ \#corresponding author \\ Type of Work: Peer Reviewed. \\ DOI: 10.21013/jas.v17.n1.p1 \\ DOI URL: https://dx.doi.org/10.21013/jas.v17.n1.p1
}

${ }^{2}$ Laboratory of Semiconductors and Solar Energy, Physics Department, Faculty of Science and

\section{How to cite this paper:}

Mame Fadiamé THIAM, Seydou FAYE, Babou DIONE (2022). Study of the Optimum Thermal Insulation Thickness of a Calorimeter Wound with Linen Insulation. IRA-International Journal of Applied Sciences (ISSN 2455-4499), 17(1), 1-6. DOI: https://dx.doi.org/10.21013/jas.v17.n1.p1

(C) IRA Academico Research.

(c) B EY-Nc This work is licensed under a Creative Commons Attribution-NonCommercial 4.0 International License subject to a proper citation to the publication source of the work.

Disclaimer: The scholarly papers as reviewed and published by IRA Academico Research are the views and opinions of their respective authors and are not the views or opinions of IRA Academico Research. IRA Academico Research disclaims any harm or loss caused due to the published content to any party.

IRA Academico Research is an institutional publisher member of Publishers International Linking Association Inc. (PILA-CrossRef), USA. IRA Academico Research is an institutional signatory to the Budapest Open Access Initiative. Hungary advocating the open access of scientific and scholarly knowledge. IRA Academico Research is also a registered content provider under Open Access Initiative Protocol for Metadata Harvesting (OAl-PMH).

This paper is peer-reviewed under IRA Academico Research's Peer Review Program.

Babou DIONE (iD)/0000-0002-5367-0839 


\begin{abstract}
In this article, the object of the study is focused on the influence of local insulating materials in the design of a calorific model for the conservation of hot water for a fixed period. The short hollow cylinder is wound with thermal insulation flax between the two walls of the cylindrical device to insulate the interior temperature. The objective of this study is to see the behavior of the thermal resistance of the material as a function of the insulation thickness. The cylinder is modeled by applying the transient analytical method with the heat equation. This analytical resolution of the thermal equation makes it possible to determine the detailed expression of the thermal resistance but also to visualize the evolution curves of this resistance according to the thickness of the insulation under the influence of the contact resistance thermal and heat exchange coefficient on the outside cylinder wall. The results obtained show that the optimum insulation thickness of linen at a temperature of $90^{\circ} \mathrm{C}$ is $3.7 \mathrm{~cm}$ under the influence of the thermal resistance of the material and $4 \mathrm{~cm}$ under the influence of the exchange coefficients thermal.
\end{abstract}

Keywords: Analytical method, transitional system, contact thermal resistance, coefficient of thermal exchange

\title{
Introduction
}

The conductive thermal resistance, also called conductive thermal resistance, of an element expresses its resistance to the passage of a heat conduction flow. Indeed, this resistance applies to solids, liquids, and gases. In the international system of units, it is given in Kelvin per Watt $(\mathrm{K} / \mathrm{W})$ or $\operatorname{per}\left({ }^{\circ} \mathrm{C} / \mathrm{W}\right)$.

The analogy between electrical quantities and thermal quantities has been the subject of several studies. Among these studies, there is the determination of shunt resistance and series resistance [7] in frequency dynamics and transient dynamics [8] of different insulating materials with different models.

In fact, this same analogy allows us to propose a study of the thermal resistance [6] of flax in a transient regime. To carry out this work, we first show the table of correspondence between electrical quantities and thermal quantities. Then, we evaluate the resistive behavior of the flax material by an analytical method [2,3] from the resistance curves under the influence of the contact resistance between water and the internal wall of the calorimeter and the coefficient of heat exchange with the outer wall of the cylinder. This study makes it possible to determine the optimum depth of the calorimeter $[1,4]$.

\section{Mathematical model and theoretical study:}

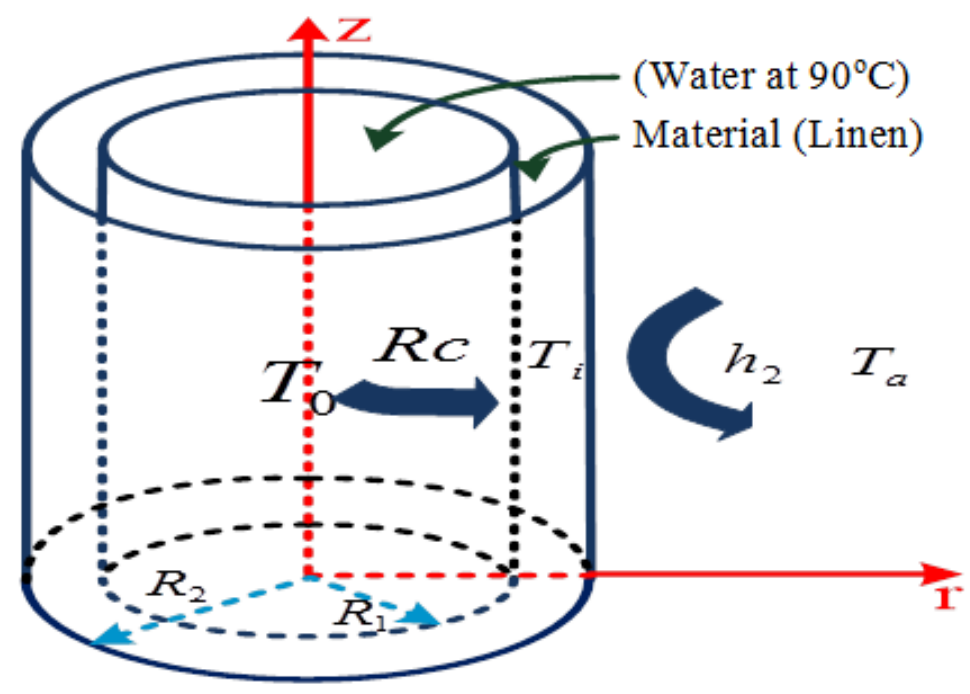

Figure 1: Experimental set-up, hollow linen cylinder

$\mathrm{R}_{1} \leq \mathrm{e} \leq \mathrm{R}_{2} ; 0 \leq \mathrm{z} \leq \mathrm{H} ; \quad \mathrm{R}_{1}=0,02 \mathrm{~m} ; \mathrm{R}_{2}=0.06 ; \mathrm{H}=0,07 \mathrm{~m}$ 
$h_{1}$ and $h_{2}$ are respectively the heat exchange coefficients at the inner and outer wall; $T_{0}$ and $T_{a}$ the ambient temperatures following the radial direction $\mathrm{r}$ inside and outside the cylinder with $T_{0}=90^{\circ} \mathrm{C}$ and $T_{a}=35^{\circ} \mathrm{C}$, $T_{i}=25^{\circ} \mathrm{C}$ The initial temperature of the material

The equation for heat without a heat source or sink is given by the following expression:

$\frac{\partial T}{\partial r^{2}}+\frac{1}{r} \frac{\partial T}{\partial r}+\frac{1}{r^{2}} \frac{\partial T}{\partial \theta^{2}}+\frac{\partial T}{\partial z^{2}}-\frac{1}{\alpha} \frac{\partial T}{\partial t}=0$

$\mathrm{T}=\mathrm{T}(\mathrm{r}, \mathrm{z}, \mathrm{t})$ the temperature at any point of the material

Ti: initial temperature of the material

$\alpha=\frac{\lambda}{\rho . c}:$ is the coefficient of thermal diffusivity $\left(\mathrm{m}^{2} \mathrm{~s}^{-1}\right)$.

$\lambda$ : is the thermal conductivity (W.m-1) and is the density of the material

The boundary conditions at the two faces along the radial axis are:

$$
\begin{aligned}
& \left.\frac{\lambda \partial T}{\partial r}\right|_{r=R_{1}}=\frac{1}{R_{C}}\left[T\left(R_{1}, z, t\right)-T_{0}\right] \\
& -\left.\frac{\lambda \partial T}{\partial r}\right|_{r=R_{2}}=h_{2}\left[T\left(R_{2}, z, t\right)-T_{a}\right]
\end{aligned}
$$

The boundary conditions on the two faces according to the height of the cylinder are:

$$
\begin{aligned}
& \left.\frac{\lambda \partial T}{\partial z}\right|_{z=0}=h_{3}\left[T(r, 0, t)-T_{i}\right] \\
& -\left.\frac{\lambda \partial T}{\partial z}\right|_{z=H}=h_{4}\left[T(r, H, t)-T_{i}\right]
\end{aligned}
$$

The initial condition:

$T(r, z, 0)=T_{i}$

The thermal resistance which is the ratio between the variation of the temperature and the density of the thermal flow is given by the relation (III-1).

$$
R_{t h}\left(r, z, R_{C_{1}}, h_{2}, t\right)=\frac{\Delta T\left(r, z, R_{C}, h_{2}, t\right)}{\Phi\left(r, z, R_{C_{1}}, h_{2}, t\right)}
$$

$\Delta T\left(r, z, h_{1}, h_{2}, t\right)$ being the temperature difference between the two sides of the linen fabric.

$\Phi\left(r, z, h_{1}, h_{2}, t\right)$ the heat flow that passes through the laundry.

The expression of thermal resistance is therefore obtained as a function of various thermophysical parameters.

$$
R_{t h}\left(r, z, R_{C}, h_{2}, t\right)=\frac{T\left(0.02,0, R_{C_{1}}, h_{2}, t\right)-T\left(r, z, R_{C_{1}}, h_{2}, t\right)}{\Phi\left(r, z, R_{C_{1}}, h_{2}, t\right)}
$$


Table 1: Correspondence table between electrical and thermal quantities

\begin{tabular}{|c|c|}
\hline Electrical quantities & Thermal quantities \\
\hline Electric current I (A) & Heat flux density $\Phi\left(\mathrm{W} / \mathrm{m}^{2}\right)$ \\
\hline Electric tension $\mathrm{U}(\mathrm{v})$ & Temperaturedifference $\Delta \mathrm{T}(\mathrm{K}+)$ \\
\hline Electric capacity $\mathrm{C}$ & Thermal capacity $\mathrm{C}_{\mathrm{th}}\left(\mathrm{J} / \mathrm{m}^{2}\right)$ \\
\hline Electricalresistance $\mathrm{R}(\Omega)$ & Thermal resistance $\mathrm{R}_{\mathrm{th}}\left(\mathrm{m}^{2} \mathrm{~W} / \mathrm{K}\right)$ \\
\hline
\end{tabular}

\section{Results and Discussions}

\section{a) Influence of thermal contact resistance}

We study the influence of the heat exchange coefficient at the level of the external wall of the cylinder h1 on the evolution of the thermal resistance of the material in depth.

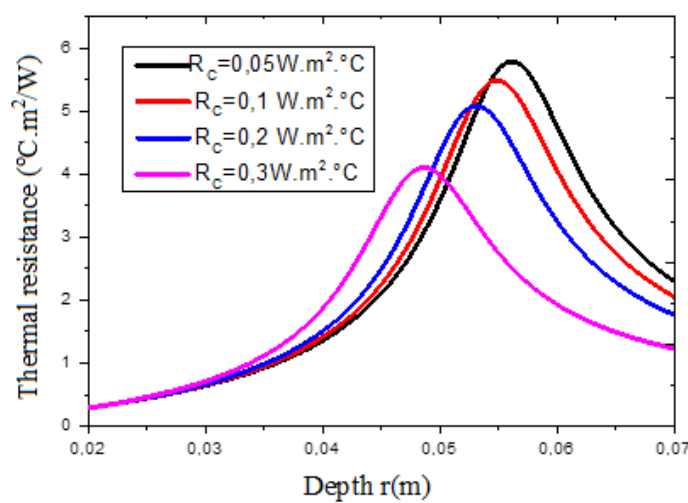

Figure 2: Evolution of the thermal resistance as a function of the depth-influences of the thermal contact resistance between the water and the inner wall of the cylinder RC

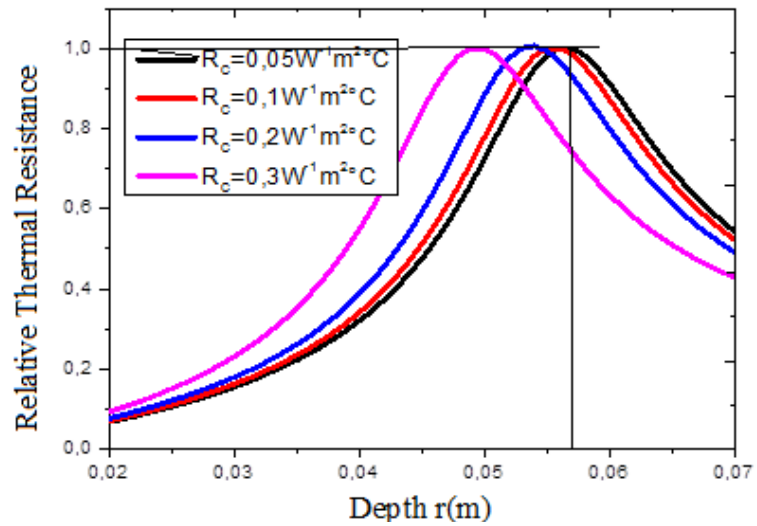

Figure 3: Evolution of the constant relative resistance as a function of depth-influence of the thermal resistance of contact between the water and the inner wall of the cylinder $\mathrm{RC}, \mathrm{h} 2=5 \mathrm{WM}-1^{\circ} \mathrm{C}-1$

Figure 2 shows the evolution of the thermal resistance in the depth of the material. The resistive behavior of the material depends on the thickness the material. For thicknesses between 0 and $2 \mathrm{~cm}$, the resistance of the material is very low, therefore the heat passes through these thicknesses due to the proximity of the inner wall of the cylinder which has the highest temperature. These characterize the area sensitive to the internal climatic stress of the cylinder.

For thicknesses between $2 \mathrm{~cm}$ and the optimum thickness, the resistance of the material increases and reaches a maximum. This phenomenon reflects the retention of heat. This shows the good thermal inertia of the material. The maximum reached by the resistance characterizes the thermal shunt effect, that is to say, the thermal blocking of heat. This took place from the optimum thickness of insulation.

With regard to thicknesses greater than optimum insulation, thermal resistance decreases, this reduction reflects heat leakage to the outside environment. It is due to the weak exchanges between the outer wall and the calorimeter.

The following table shows the optimum insulation thickness and the corresponding thermal resistance. 
Table 2: Influence of thermal contact resistance on thermal resistance and insulation thickness

\begin{tabular}{|c|c|c|c|c|}
\hline $\begin{array}{c}\text { Thermal contact resistance } \mathrm{R}_{\mathrm{C}} \\
\left(\mathrm{m}^{2} \mathrm{C} / \mathrm{W}\right)\end{array}$ & 0.3 & 0.2 & 0.1 & 0.05 \\
\hline $\begin{array}{c}\text { Thermal resistance } \\
\mathrm{R}\left(\mathrm{m}^{2 \circ} \mathrm{C} / \mathrm{W}\right)\end{array}$ & 4.17 & 5.08 & 5.434 & 5.82 \\
\hline $\begin{array}{c}\text { Optimal insulation thickness rop } \\
(\mathrm{m})\end{array}$ & 0.029 & 0.034 & 0.036 & 0.037 \\
\hline $\begin{array}{c}\text { Percentage of insulation } \\
\text { thickness }\end{array}$ & 48,33 & 56,66 & 60 & 61,66 \\
\hline
\end{tabular}

b. Influence of the exchange coefficient on the outer wall of the cylinder.

We show the influence of the heat exchange coefficient on the outer wall of the calorimeter.

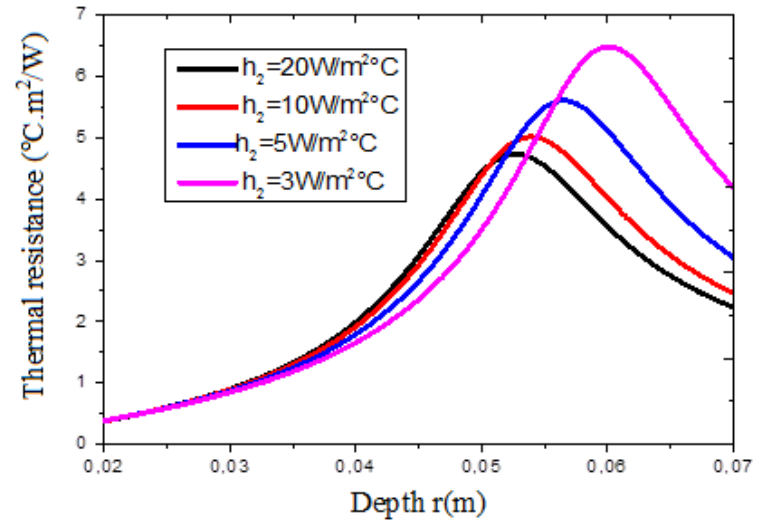

Figure 4: Evolution of thermal resistance as a function of depth-influences of the heat exchange coefficient $\mathrm{h} 2$, $\mathrm{R}_{\mathrm{C}}=0.05 \mathrm{~W}^{-1} \mathrm{~m}^{2}{ }^{\circ} \mathrm{C} ; \mathrm{t}=100 \mathrm{~s} ; \mathrm{z}=0.03 \mathrm{~m}$

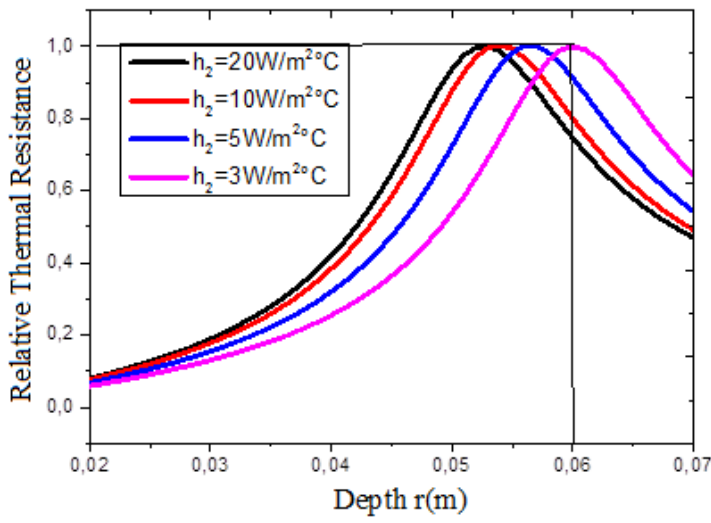

Figure 5: Evolution of the relative resistance as a function of the depth-influence of the heat exchange coefficient $\mathrm{h} 2 . \mathrm{R}_{\mathrm{C}}=0.05 \mathrm{~W}^{-1} \mathrm{~m}^{2}{ }^{\circ} \mathrm{C} ; \mathrm{t}=100 \mathrm{~s} ; \mathrm{z}=0.03 \mathrm{~m}$

Figure 4 shows the resistive behavior depending on the depth of linen material. Note that the resistance of the linen material is appreciably low for thicknesses very close to the inner wall of the cylinder; this is the area sensitive to climatic stresses from the heat flow inside the cylinder. The coefficients of exchange at the inner wall have no effect on the resistance in this area.

On the other hand, for thicknesses greater than $2 \mathrm{~cm}$, the thermal resistance increases in-depth with the decrease in the exchange coefficient and reaches a maximum. This maximum reflects the phenomenon of heat retention and blocking of heat flow. Low values of the heat exchange coefficient lead to an increase in the thermal resistance of the material, which is due to the fact that the exchange coefficients at the outer wall cool the flax. The decrease in thermal resistance in the vicinity of the outer wall reflects heat leaks to the outside environment.

Table 3: Influence of the $\mathrm{h} 2$ coefficient on thermal resistance and optimum insulation thickness

\begin{tabular}{|c|c|c|c|c|}
\hline $\begin{array}{c}\text { Exchange coefficient } \mathrm{h}_{2} \\
\left(\mathrm{~W} / \mathrm{m}^{2}{ }^{\circ} \mathrm{C}\right)\end{array}$ & 3 & 5 & 10 & 20 \\
\hline $\begin{array}{c}\text { Thermal resistance } \\
\left({ }^{\circ} \mathrm{C} . \mathrm{m}^{2} / \mathrm{W}\right)\end{array}$ & 6.506 & 5.636 & 5.031 & 4.734 \\
\hline $\begin{array}{c}\text { Optimal insulation } \\
\text { thicknessrop(m) }\end{array}$ & 0.04 & 0.036 & 0.034 & 0.032 \\
\hline $\begin{array}{c}\text { Percentage of insulation } \\
\text { thickness }\end{array}$ & 66,66 & 60 & 56,66 & 53,33 \\
\hline
\end{tabular}

\section{Conclusion}

This work was devoted to the study of the behavior of the thermal resistance of flax. In accordance with the objectives pursued, we have succeeded in determining the optimum insulation thickness of the calorimeter in which we can obtain good thermal insulation. Also, we have shown that resistance depends on the thickness of 
the material. The influence of thermal contact resistance and heat exchange coefficient has been highlighted on the behavior of thermal resistance.

\section{References}

[1]. Seguin, J. P. Gosse, Dispositif de mesure calorimétrique des pertes dans les condensateurs de puissance, Journal de Physique III France, (1997) 321-336. [25] E. https://doi.org/10.1051/jp3:1997125

[2]. A. GUREL, A. DASDEMIR. Economical and environmental effects of thermal insulation thickness in four different climatic regions of Turkey. International Journal of Renewable Energy Research.Vol.1, No.1, pp.110,2011

[3]. Cheikh Tidiane Sarr, Issa Diagne, Mamadou Lamine Sow, (2009) « Caractérisation des isolants thermiques cylindriques par une méthode analogique : Application au Kapok» J. Sci Vol. 9, N³, 32-46.

[4]. D. CHRISTEN -U. BADSTUEBNER - J. BIELA - J.W. KOLAR - Calorimetric power loss measurement for highly efficient converters - The 2010 International Power Electronics Conference (IPEC), pp. 1438 1445, 2010. https://doi.org/10.1109/IPEC.2010.5544503

[5]. A. SALEH, M. MOSA. Analysis of control strategies and simulation of heating systems using Simulink/ Matlab potential-Journal of Thermal Engineering. Vol. 2, No. 5, Oct 2016. pp. 921-927. https://doi.org/10.18186/jte.97874

[6]. Y. TRAORE, I. DIAGNE, C. SARR, M. S. OULD BRAHIM, A. K. DIALLO, H. LY DIALLO, AND G. SISSOKO. Influence of thermal exchange coefficient on the heat retention rate of a concrete wall contiguous to a thermal insulation tow-plaster. ARPN Journal of Engineering and Applied Sciences. Vol. 11, $\mathrm{N}^{\circ}$, 2016.

[7]. LEFEBVRE, G. (1989). Caractérisation de l'inertie thermique d'un bâtiment par analyse modale. Revue general de thermique, 28:501-51.

[8]. JAKOSKY, B. M., M. T. Mellon, H. H. Kieffer, P. R. Christensen, E. S. Varnes, and S. W. Lee (2000), The thermal inertia of Mars from the Mars global surveyor thermal emission spectrometer, J. Geophys. Res., 105, 9643 - 9652. https://doi.org/10.1029/1999JE001088 